\title{
Renovación urbana y gentrificación post-catástrofe en Concepción: el caso Aurora de Chile ${ }^{1}$ \\ Urban renewal and post catastrophe gentrification in Concepcion: the case of Aurora de Chile \\ Christian Matus, Rodrigo Ganter, Camila Barraza y Constansa Vergara
}

\section{Filiación}

Universidad de Concepción, Chile

E mail: christianmatus@udec.cl,rganter@udec.cl, camila.ebh@gmail.com,constansavergara@gmail.com

Primera versión recibida en: 04 de abril, 2016

Última versión recibida en: 22 de junio, 2016

\section{RESUMEN}

El estudio de caso de la Población Aurora de Chile evidencia la existencia de una estrategia de renovación urbana que promueve la gentrificación y que utiliza el desastre como una herramienta simbólica para justificar el desarrollo de operaciones urbanas que generan desplazamientos. A través de una metodología de revisión de instrumentos de planificación urbana, entrevistas a informantes clave y grupos de conversación con pobladores, se indagan las diferentes etapas del proceso de renovación urbana, que dan cuenta de los discursos y construcciones simbólicas sobre la ciudad y su desarrollo post catástrofe. Finalmente, se plantea la existencia de una estrategia de renovación urbana no explicitada en un proyecto de planificación, que utiliza el Terremoto como oportunidad para gatillar la aceleración de proyectos público-privados, que son impuestos a la comunidad, naturalizando la necesidad de que Aurora "sacrifique" su territorio por el bien común y desarrollo de la ciudad.

\section{Palabras clave}

Gentrificación; reconstrucción; renovación urbana.

\begin{abstract}
The study of Aurora de Chile reveals the existence of a gentrification process associated to urban renewal policies and natural disasters - earthquakes- in the riverfront neighborhood of Aurora, as symbolic tools that justify the development of urban operations that are being implemented without participatory strategies. Through a methodology based on the revision of urban planning instruments, ethnographic observations, interviews to key informants and neighbor conversation groups, the different phases of the urban renewal process were analyzed, noting the arguments related to planning and reconstruction, and how these symbolic constructions determine the expression, of the different actors involved, regarding the city and its post catastrophe development. Finally it is proposed that a strategy of urban renewal of the riverfront exists, and that it uses the earthquake as an opportunity to trigger the acceleration of joint public and private projects, but it's not made explicit in an urban planning project. Thus, naturalizing the need that the inhabitants of this urban village "sacrifice" part of their land and identity for the good and future development of the city.
\end{abstract}

\section{KEYWORDS}

Gentrification; reconstruction; urban renewal

\footnotetext{
${ }^{1}$ El presente artículo se desarrolló en el contexto del Proyecto CONICYT/FONDAP №15110020 en el marco del plan de investigación postdoctoral del autor principal.
} 


\title{
Sumario
}

\author{
Introducción
}

1 El problema de investigación y la metodología de abordaje

2 Aurora de Chile como caso de estudio: una población histórica en proceso de desplazamiento

3 La Población Aurora de Chile en el contexto de la Renovación Urbana de la Costanera del Biobío

3.1 Primera Etapa: Fase de Renovación Urbana Público-Privada. (Plan Ribera Norte 19902007)

3.2 Segunda Etapa: Fase de Renovación Urbana Desregulada Post Ribera Norte (2007- 2015). El Puente Chacabuco y la catástrofe como detonantes del proceso de desplazamiento de Aurora de Chile

$4 \quad$ La construcción simbólica sobre el desplazamiento post-catástrofe: entre la "naturalización", la negociación y la resistencia

5 Conclusiones

Bibliografía

\section{I ntroducción}

A partir de la década de los noventa, los estudios urbanos empiezan a abordar en forma consistente el análisis de los impactos territoriales que generan los procesos económicos globalizadores, a nivel - primero- de las metrópolis y luego, de las ciudades intermedias. En ese marco se va configurando una mirada crítica que da cuenta del impacto de las políticas neoliberales en la forma de construir ciudad. Brenner y Theodore $(2005,2002)$ sistematizan las principales características del modelo de desarrollo urbano neoliberal, dadas por: (i) la creación de redes de negocios dirigidas por colaboraciones público-privadas; (ii) nuevas formas de política de desarrollo económico local que fomenta la cooperación entre las empresas; (iii) la implementación de programas basados en la comunidad para paliar la exclusión social, (iv) la promoción de nuevas formas de coordinación interinstitucional y creación de redes entre las distintas esferas anteriores a la intervención estatal local, y (v) la formación de nuevas instituciones regionales que promueven la coordinación intergubernamental y el marketing urbano.

En ese marco de acción, las políticas de renovación urbana de los centros de las ciudades se configuran en base a una marcada tendencia al "empresarialismo" (Harvey, 1989) o desarrollo de consorcios público-privados (Vainer 2000; Fainstein 1994), integrados por administradores locales, empresas y organizaciones privadas, agencias de cooperación internacional, y el público usuario que demanda el uso de los territorios céntricos, potenciándose los efectos gentrificadores de la renovación a partir del uso de diferentes herramientas como subsidios de vivienda, inversiones inmobiliarias y rehabilitación de espacios anteriormente deprimidos.

El análisis del modelo de la planificación neoliberal tiende a visibilizar cada vez más una consistente articulación entre las políticas urbanas de renovación urbana y el desarrollo de nuevas formas de gentrificación y desplazamiento. Siguiendo a Davidson y Lees (2010) existe consenso de que la presencia de cuatro condiciones, que permiten categorizar el impacto de los procesos de renovación urbana como efectos de gentrificación: a) desplazamiento directo o indirecto de grupos sociales de ingresos bajos; b) re-inversión de capital; c) entrada de grupos sociales de más altos ingresos, y d) generar cambios en el paisaje urbano. 
En el contexto de la hegemonía del modelo de desarrollo urbano neoliberal, la discusión contemporánea sobre gentrificación tiende cada vez más a entenderla como un proceso múltiple, que incluye acciones de desplazamiento directo e indirecto en las que "ambas poseen en común la alteración de la naturaleza de clases basada en barrios ampliados" (Davidson and Lees, 2010: 408; Janoschka et al., 2013). Como evidencian recientes estudios de caso a nivel iberoamericano y latinoamericano (Aricó, Mansilla \& Luca, 2015, Janoshcka \& Hidalgo, 2014), la gentrificación en sus más diversas manifestaciones, constituye el principal mecanismo de gestión del urbanismo neoliberal; un proceso que permanece oculto o "naturalizado" bajo conceptos amplios y ambiguos como regeneración, revitalización o renacimiento urbano. Citando a Marcuse (1985) se podría plantear que los discursos hegemónicos de la planificación, tienden a ocultar deliberadamente la gentrificación, y "naturalizarla", planteando el abandono como un proceso inevitable, que no se puede revertir por las políticas públicas; sosteniendo que ésta mejora la calidad de la vivienda y revitaliza áreas urbanas gracias a la inversión privada; o planteando que es la única solución realista para convertir barrios abandonados en barrios vitales y activos.

No obstante, la neoliberalización de las ciudades, constituye un proceso que no obedece a un patrón lineal, sino que responde a ensamblajes políticos particulares (Theodore, Peck \& Brenner, 2009), que tienen que ver con los contextos específicos que asume la implantación del neoliberalismo en cada uno de los espacios urbanos. Para el caso chileno resulta clave evidenciar que es el país en donde se inician las políticas de shock neoliberal (Klein, 2007) plasmadas a nivel urbano en la reformulación que la Dictadura hace en 1979 del mercado del suelo, al dejar de considerarlo un bien escaso (Sabatini, 2000). En ese sentido se puede plantear que las políticas urbanas de las ciudades chilenas han vivido más de tres décadas de influjo y hegemonía de un neoliberalismo extremo, aplicado sin ningún contrapeso público.

En el marco de la extrema neoliberalización que afecta a las ciudades latinoamericanas en las últimas dos décadas, se sitúa la tendencia a la proliferación de políticas públicas urbanas que tienen como objetivo (explícito o implícito), desplazar a las clases populares de las áreas centrales (Sequera, 2015; Janoschka \& Sequera, 2014). En ese contexto sectores estratégicos de los centros urbanos, tienden a ser abandonados más aún si son sujetos a catástrofes, de modo de potenciar la emergencia de vacíos urbanos en espera de un nuevo desarrollo inmobiliario.

Los estudios sobre procesos de reconstrucción a nivel iberoamericano más recientes tienden a aportar evidencia del uso de la gentrificación como herramienta de gestión urbana para la reconstrucción de ciudades intermedias sujetas a catástrofes, tales como Managua (Inzulza y López, 2014) y particularmente la reconstrucción de ciudades intermedias desarrolladas post terremoto y tsunami del 27 de Febrero de 2010 en Chile (Inzulza 2014; Letelier \& Boyco, 2013). El análisis particular de cómo los procesos de reconstrucción articulan su planificación con el desarrollo de desplazamientos directos e indirectos de comunidades, abre el debate sobre cómo las tipologías de gentrificación contemporánea están siendo aplicadas para rehabilitar las áreas centrales a través de consorcios público-privados, que actúan en nombre de la regeneración urbana y mejoramiento de ciudades (Inzulza, 2012).

Como plantea Delgadillo (2015), a diferencia de la experiencia europea, en Latinoamérica, las políticas urbanas tienden a diversificar sus modalidades de desplazamiento, yendo más allá de la definición estandarizada de procesos de cambio planificado en un barrio en situación de decadencia o deterioro, diferenciándose por el desarrollo de un conjunto heterogéneo de estrategias de desplazamiento, que aprovechan oportunidades y contextos específicos para su aceleración. Analizando su tipología de desplazamientos, es posible visibilizar al menos dos 
variantes particularmente visibles en las ciudades intermedias y que son claramente aplicables a las ciudades chilenas que han sido azotadas por catástrofes naturales como aconteció en la VIII Región, y en particular en Concepción. Por un lado, el desplazamiento de población por desastres naturales (Audefroy y Ottolini, 1999) y por otro, el efecto del desarrollo de proyectos públicos y privados de renovación urbana (Ottolini y Berger, 1999). En el primer lugar, se plantea el ejemplo de desalojos por desastres sociales derivados de algún fenómeno natural. Un sismo, una inundación u otra calamidad "natural", es una oportunidad para "liberar" territorios apetecibles y "solucionar" el problema de los pobres en las periferias urbanas, a través de ayudas públicas. En el segundo caso, se trata de desalojos por la realización de proyectos públicos o/y privados de renovación urbana, recuperación de centros y barrios históricos, creación de parques urbanos, saneamiento de áreas inundables, apertura de espacio público (plazas, ramblas, bulevares, etcétera).

Finalmente, cabe señalar que, así como las expresiones de procesos gentrificadores se diversifican en el contexto de la ciudad neoliberal latinoamericana, es la propia ciudadanía la que se moviliza, resiste y denuncia los procesos de exclusión a través de disputas urbanas, dando cuenta de los efectos negativos del desplazamiento. Es así como estudios como Holston (2009) para Brasil, y Paulsen (2014) para Chile, han demostrado cómo las clases populares son las mayormente afectadas, pero también las más activas y contestatarias para enfrentar, a través del conflicto urbano, procesos de gentrificación que evidencian los impactos de las políticas neoliberales en grupos sociales con menores ingresos. Mitchell (2003) y Holston (2009) relacionan estas luchas urbanas con el ejercicio por parte de las poblaciones y movimientos del "derecho a la ciudad", retomando el enfoque planteado por Lefebvre (1975), y actualizado hoy por Harvey (2008).

\section{El problema de investigación y la metodología de abordaje}

Considerando lo anterior, se plantea indagar acerca de la articulación existente entre procesos de renovación urbana, desplazamiento de sectores populares y gentrificación, en el contexto de la Costanera de Concepción. En ese marco se propone analizar de qué manera el conflicto de Aurora de Chile constituye un ejemplo de implementación de política neoliberal de renovación urbana, con efectos gentrificadores, que plantean como requisito para su desarrollo el desplazamiento de población originaria. A modo de preguntas de investigación, interesa conocer ¿cómo se ha desarrollado en Concepción el proceso de renovación urbana de la Costanera?, ¿cuáles son los principales efectos sociales y espaciales que dicho proceso plantea para la Población Aurora de Chile?, ¿pueden estos efectos sociales y espaciales ser entendidos en el presente como el desarrollo de una estrategia de desplazamiento asociada a un proceso de gentrificación en curso?, ¿de qué manera la catástrofe opera como un contexto de oportunidad que acelera el desplazamiento de la población que se encontraba detenido desde el Plan Ribera Norte?, y finalmente, ¿qué discursos simbólicos construyen los diferentes actores involucrados para legitimar o resistir el desplazamiento de la población de la Costanera?

Se propone como objetivo de estudio, reconstruir, a través de un estudio de caso, el conflicto de Aurora de Chile y el Puente Chacabuco, de modo de dar cuenta como este es expresión de una política neoliberal de renovación urbana que articula desplazamiento y gentrificación. Para cumplir con dicho objetivo, se estructuró una estrategia de investigación de enfoque mixto (Sampieri et al, 2007) que consideró la combinación de revisión de fuentes secundarias referidas a planes de renovación urbana, seccionales y planes reguladores metropolitano y 
comunal $^{2}$, con el diseño e implementación de un plan de acompañamiento sostenido por el equipo CEDEUS con la comunidad representada por la Junta de Vecinos de Aurora de Chile, implementado durante seis meses, entre abril y septiembre de 2015. El trabajo de campo realizado con la comunidad se sitúa en el marco de una investigación de acción participativa (Fals Borda, 2007), que consideró reuniones semanales tendientes a problematizar el conflicto y asesorar a la comunidad en el desarrollo de negociaciones con MINVU; se realizó una encuesta y mapeo de lugares valiosos; una ruta patrimonial en el día Nacional del Patrimonio; y el co-diseño e implementación de cuatro talleres de conversación grupal con los pobladores, desarrollados en torno a la reconstrucción de la relación de la población con la ciudad de Concepción y la política pública del Estado, y la visión de futuro de la población Aurora de Chile (CEDEUS, 2015).

Complementariamente se desarrollaron entrevistas semi-estructuradas tendientes a sistematizar el caso en base a 5 informantes clave, considerando pobladores, representantes del municipio, MINVU y dos urbanistas expertos. La pauta de entrevista aplicada tuvo por objetivo indagar en las representaciones y percepciones de cada uno de los actores sobre el desarrollo de los proyectos de renovación y visiones de futuro construidas sobre la Costanera de Concepción los últimos veinticinco años.

En las siguientes secciones se aborda el contexto histórico de Aurora de Chile en relación con la ciudad de Concepción, para luego presentar una reconstrucción crítica del proceso de renovación urbana en la Costanera, sus impactos socio-territoriales y su relación con el conflicto urbano gatillado por la construcción del Puente Chacabuco. Posteriormente, se analizan los discursos que construyen autoridades, urbanistas y pobladores sobre los procesos de renovación y desplazamiento que gatilla la construcción del puente, para finalizar planteando, a nivel de conclusiones, los efectos socio-espaciales que plantea la renovación de la Costanera de Concepción, y en particular el plan de erradicación de Aurora, desarrollado post-terremoto, en términos de desplazamiento y gentrificación.

\section{Aurora de Chile como caso de estudio: una población histórica en proceso de desplazamiento}

Aurora de Chile configura un asentamiento urbano instalado de forma espontánea en la Ribera Norte del Río Biobío hace más de 75 años, formando parte de la ciudad de Concepción, ciudad intermedia del sur de Chile, poblada por 214.234 habitantes (Censo 2012, Informe Preliminar), que forma parte del Área Metropolitana de Concepción (AMC) junto a una red de otras ocho comunas urbanas (Coronel, Chiguayante, Lota, Penco, San Pedro de la Paz, Talcahuano, Tomé y la nueva comuna de Hualpén).

En la actualidad, Aurora ocupa un área aproximada de 12 manzanas, en las que viven un número aproximado de 3500 personas distribuidas en 650 familias (Catastro MINVU 2015). Su emplazamiento en la Costanera, está relacionado con el proceso de industrialización que vivió la ciudad de Concepción a partir de la primera mitad del siglo XX, que llevó a que la ciudad experimentara un importante desarrollo, generando el incentivo para que se desarrollaran olas de migración campo-ciudad y se establecieran los primeros asentamientos populares espontáneos en la periferia de la ciudad. Uno de los sectores donde se desarrollan estas prácticas de asentamiento de un hábitat popular (Peyloubet et al. 2006) es la Costanera de

2 Se revisó la Memoria del Plan Ribera Norte (MINVU, 2001), el Seccional Ribera Norte (2009), y una revisión de prensa del período 2010-2015 utilizando como fuentes documentales, los diarios, El Sur y Diario de Concepción, y para reconstituir las movilizaciones de los pobladores el periódico electrónico El Resumen. 
Concepción, sector que comprende la ribera del río Biobío desde el Cerro Chepe hasta el sector de La Mocha, y que fue habitado durante el siglo XX por otros asentamientos urbanos como la Población Pedro Del Río y Pedro de Valdivia Bajo (Lasalle \& Cabrera, 2000)

La construcción de la línea de Ferrocarriles (1873), del Puente Carretero (1935) y la instalación de importantes centros industriales como la Fábrica de Paños Biobío (1919), fueron fundamentales para consolidar la Costanera de Concepción demarcando sus límites urbanos, prestando las primeras señales de urbanización e incentivando la llegada de nuevos habitantes. (Lasalle y Cabrera 2000; Olguín 2011; Fernández 2015).

La ocupación histórica de la Costanera por parte de los pobladores, tuvo la particularidad de desarrollarse en la ribera del Biobío, en un lugar inundable de características no habitables, lo que significó que las personas que llegaban a habitar el espacio, tuvieran que desarrollar técnicas de auto-construcción, siendo una de las más características la de construir la vivienda en forma de palafito sobre el río, respondiendo primero a la necesidad de contar con un techo para vivir, para luego ir sedimentando el terreno con diversos materiales. Es importante relevar que es después de los terremotos de 1939 (Chillán) y 1960 (Valdivia) cuando se consolida la ocupación del sector, con la llegada de población afectada que desarrolla rellenos que se hacen más sólidos al contar con gran cantidad escombros dejados por las catástrofes. Esto generó la necesidad de ordenar el espacio, proceso que se desarrolló respetando el damero existente, dejando en evidencia cómo a pesar del límite del ferrocarril, los pobladores se integran a la ciudad dando continuidad a la trama urbana de Concepción. Todos estos procesos de urbanización popular son desarrollados mediante trabajo autogestionado, que considera la instalación de red eléctrica y de alcantarillado, integrando la población a la red existente de la fábrica Biobío, y haciendo las conexiones al servicio de agua potable, lo que significó también ir mejorando durante el tiempo las condiciones de viviendas y espacios comunitarios como el club deportivo Huracán, la junta de vecinos, talleres de mujeres, y organizaciones religiosas (Ferrada 2011; Olguín 2011). La llegada paulatina de nuevas generaciones de pobladores al sector y los procesos de relleno del río, hicieron que su identidad de población se fuera conformando reconociendo distintas categorías de aurorinos, según su participación en los sucesivos ciclos de poblamiento, dando lugar a una primera generación de colonos (los fundadores de la población), y nuevas generaciones de nacidos y criados (segunda, tercera, cuarta generación).

\section{La Población Aurora de Chile en el contexto de la Renovación Urbana de la Costanera del Biobío}

A partir de fines de la década de 1980 Concepción comienza a vivir una dinámica de transformación de su forma y rol dentro del sistema urbano de la provincia del Biobío, lo que genera una revalorización de la Costanera como espacio de renovación urbana. Los procesos de metropolización, incrementados durante las últimas tres décadas, gatillan el desarrollo de nuevas formas o tipos de crecimiento urbano en el AMC (Salinas \& Pérez, 2011), que marcan una evolución de su morfología urbana caracterizada por núcleos dispersos y autocentrados a una gran área metropolitana rodeada de anillos concéntricos de ciudades satélites (San Pedro, Chiguayante entre otras). La Costanera adquiere una jerarquía más amplia como centralidad no sólo desde una perspectiva comunal, sino también como parte de una escala metropolitana que demanda comunicar en forma directa nuevos y exclusivos asentamientos urbanos de clase altas como Andalué y El Venado, situados en San Pedro, con la ciudad de Concepción convirtiéndose en un espacio central para desarrollar proyectos tanto inmobiliarios como de 
infraestructura y conectividad que articulen y den mayor dinamismo al sistema urbano y de transporte particular que conecta San Pedro con Concepción.

A continuación se presenta la reconstitución del proceso de renovación urbana desarrollado en la Costanera del Biobío entre 1990 y 2015, focalizando en las consecuencias de desplazamiento que trajo para la población Aurora. Este permitió distinguir la existencia de una primera fase configurada por la implementación de un modelo público-privado (Plan Ribera Norte), en donde la mayoría de los habitantes de Aurora decide no participar; y una segunda fase de planificación híbrida con predominio del enfoque privado, que utiliza la oportunidad del evento sísmico de 2010 para culminar el proceso de desplazamiento de población originaria, propiciando a través del Plan Aurora, la erradicación de gran parte de la población para permitir el paso del Puente Chacabuco.

\subsection{Primera Etapa: Fase de Renovación Urbana Público-Privada. (Plan Ribera Norte 1990- 2007)}

Con el retorno de la democracia, se empieza a diseñar y planificar un proceso de renovación urbana de la Costanera, que naturaliza como ideal urbano el acercamiento de la ciudad al río, asociado a una regeneración de la Ribera Norte del Río Biobío. Si bien el planteamiento de estas ideas es recurrente en la historia previa de la planificación penquista, es sólo en el contexto post-dictatorial cuando se materializan las condiciones económicas y políticas para implementar una iniciativa real de renovación.

En la década de los noventa se comienza a debatir una serie de proyectos que involucran intervenciones en la Costanera del Biobío. Es así como surge a través de una Iniciativa Presidencial del gobierno de Patricio Aylwin (1990-1993), la idea de concretar un plan de renovación para toda la Costanera. Durante el período de Aylwin se hacen los estudios de prefactibilidad del proyecto y durante el gobierno de Frei Ruiz-Tagle (1994-1999) se implementa, considerando un modelo de gestión a cargo del denominado equipo del Programa Ribera Norte, inscrito en la Dirección de Proyectos Urbanos (DPU) del MINVU, entidad que además contó con convenios de apoyo con el Programa de las Naciones Unidas para el Desarrollo (PNUD) y el Centro de las Naciones Unidas para los Asentamiento Humanos (HABITAT). A partir de lo anterior, se comienza a desarrollar un plan de carácter intercomunal en un tramo de $35 \mathrm{~km}$ de longitud que abarcó cuatro comunas del área metropolitana (Hualpén, Concepción, Chiguayante y Hualqui), y dividió el área de intervención en 6 áreasprograma a lo largo del borde río, las que consideraron la configuración de una vialidad estructurante desde Parque Hualpén hasta Hualqui, la creación de áreas verdes y salas de equipamiento, y la recuperación de terreno para áreas residenciales desde Hualpén a Chiguayante (MINVU-Plan Ribera Norte, 2001)

El Plan Ribera Norte (PRN en adelante), obedece a las características propias de la planificación urbana en el contexto de la ciudad neoliberal ya descritas por Brenner y Theodore (2005). Su diseño lo define como un proyecto emblemático de corte público-privado, que se propuso tres objetivos principales: a) dar solución habitacional a las cerca de 1500 familias que residían en el área; b) desarrollar un plan de renovación urbana que recuperara e integrara el río con la ciudad; y c) promover la inversión inmobiliaria en el área en base a una gestión financiera centrada en una lógica de autofinanciamiento ${ }^{3}$ (Memoria PRN, 2001).

3 Se trata de un modelo de gestión centrado en la venta de terrenos fiscales a privados, que impulsaría la participación de estos en el desarrollo de proyectos inmobiliarios recuperando gran parte de los recursos invertidos por el Estado, lo que daría las garantías necesarias para hacer posible la inversión en espacios públicos y en el "bien común", entendidos como elementos de rentabilidad social más que financiera. 
El PRN se implementa en un momento de auge de la gestión urbana empresarial. En ese marco se entiende su pretensión de adaptar a la realidad penquista un modelo de propuesta urbana basado en la experiencia internacional de Puerto Madero, Buenos Aires. En relación al centro de la ciudad, el plan define como "proyecto detonante" al sector denominado Área-Programa III, localizado en el entorno inmediato donde se emplaza la Población Aurora de Chile (Fig. 1), porque generaba una continuidad al centro de Concepción y ofrecía mayores garantías de generar una inversión inmobiliaria exitosa.

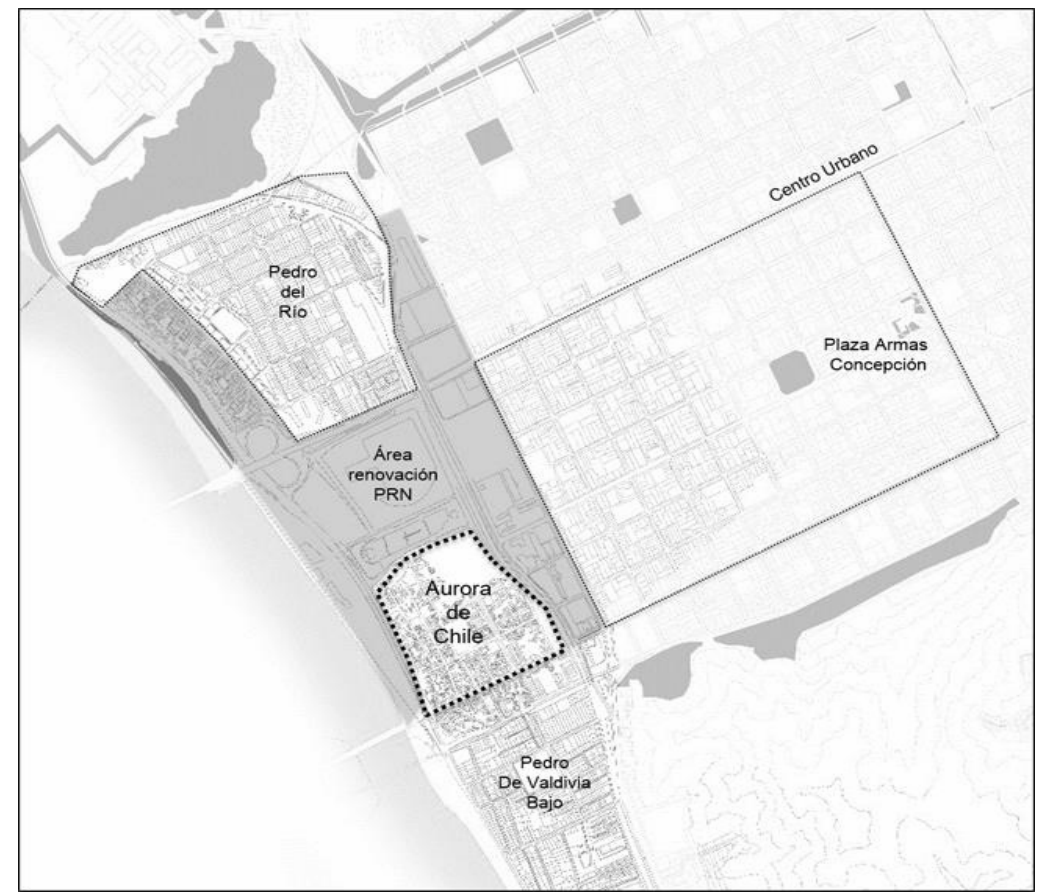

Fig. 1 Esquema Área-programa 3 PRN

Fuente: Elaboración Propia

Los estudios que abordan sus resultados tienden a evaluar positivamente su impacto social valorando la solución habitacional, la política participativa y el rol de la administración pública para llevar a cabo este objetivo (Zunino 2005; Bascur 2006; Rojas y Villagrán 2008; Flores 2013). No obstante, respecto al proceso social de radicación de comunidades, cabe señalar que si bien desarrolló un proceso de trabajo participativo con las familias que residían en el área, éste estuvo siempre subordinado al objetivo de conseguir el abandono de los pobladores de Costanera del espacio de renovación urbana, para migrar a las soluciones habitacionales ofrecidas (Rojas, 2008). Como plantea Ong (2006), el urbanismo neoliberal configura técnicas de gobernanza que establecen regímenes excepcionales de ciudadanía, instituyendo una nueva relación entre gobierno y saber, que plantea una despolitización de la esfera pública mediante procesos institucionalizados desideologizados, exentos de conflicto, basados exclusivamente en criterios técnicos. En ese sentido, los planes de renovación urbana adaptan y reconfiguran los instrumentos de intervención a los contextos y coyunturas que facilitan o dificultan sus resultados. Siguiendo lo anterior, el Plan Ribera Norte tuvo que adaptar su modelo de intervención ante la resistencia de los pobladores de dejar el área, modificando su estrategia de participación, de modo de integrar al proyecto a los pobladores que iban a ser desplazados bajo el supuesto de que mediante el desarrollo de procesos de participación técnicamente correctos, serían "convencidos" de que esta era una "solución digna" para ellos. 
Un aspecto central para entender el conflicto del Puente Chacabuco tiene que ver con los "temas pendientes" que deja el PRN en relación con la renovación del área céntrica de Costanera. A diferencia de Pedro del Río, la mayor parte de la Población Aurora de Chile no acepta incorporarse al proyecto debido a los fuertes sentimientos de pertenencia e identidad y a los efectos directos en los sistemas de economía local constituidos al margen de la legalidad, que se forjaron durante el tiempo que llevaban habitando el sector, durante el que fueron mejorando sus condiciones de vida y sus viviendas. Bajo estos conceptos materiales e inmateriales, tenían la certeza de que al irse a los proyectos ofrecidos tenían más opciones de perder que de ganar. No obstante lo anterior, a partir de la investigación sintetizada en este artículo, logramos precisar que un significativo grupo de familias se integró a la propuesta de urbanización, que determinó el desplazamiento de cerca de 530 familias de Aurora de Chile - de un total cercano a 1500 a esa fecha- que fueron radicadas en la solución del Ribera Norte, proceso que se dio de forma aleatoria en el territorio dejando sitios desocupados (Fig. 2).

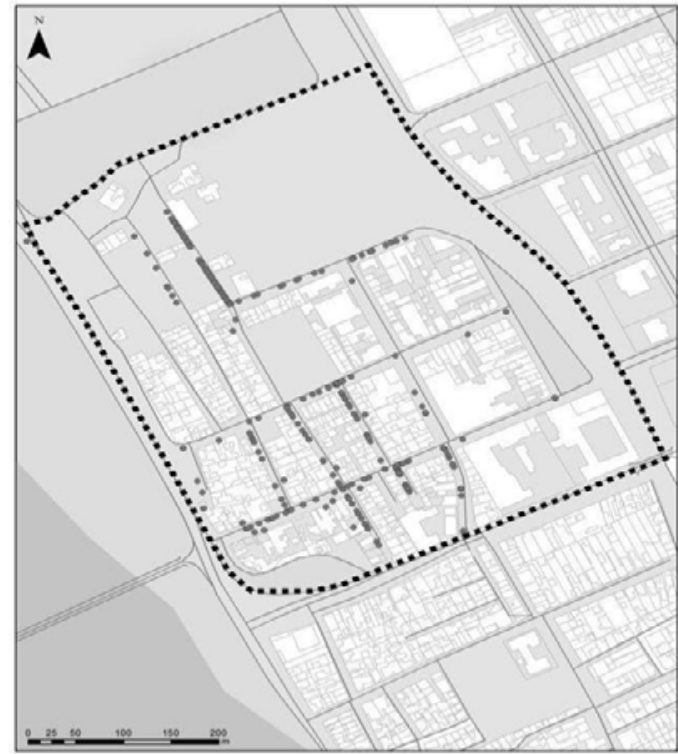

Fig. 2 Familias Población Aurora participantes en Soluciones Habitacionales PRN

Fuente: Elaboración propia en base a lista beneficiarios PRN, solicitada por ley de transparencia, SERVIU, 2014.

Este dato cuantitativo coincide con el relato cualitativo que sitúa en los "tiempos de Ribera Norte", el comienzo de la pérdida de unidad de la población. En efecto, una faceta invisible del impacto del plan tuvo relación con el efecto que generó en la vida de la población la ocupación de estos sitios por personas nuevas, afectando sus dinámicas sociales y creando situaciones de desconfianza ante los nuevos vecinos, lo que terminó por fragmentar socialmente a la población.

"Incluso hay gente que ya ha vendido sus departamentos, se han ido a otras partes, no se hayan, está muy mezclado todo, bueno los vecinos sobre todo en un edificio donde tú tienes que convivir con cuantas familias, aquí cada familia tenía su casa con su espacio, su patio y en un edificio vivir dieciséis familias o veinte no sé, es complicado y también hay edificios de departamentos buenísimos y están bien, pero son los menos, y hay otros que la sufren y penan para que se habrán ido siendo que esto todavía está y han pasado 11 años de los primeros que se fueron" (Folklorista, segunda generación) (Testimonios citados en Ferrada, C. 2011: 147) 
En efecto, estudios como los de Ferrada (2011) y Fernández (2015), evidencian que las familias de Aurora trasladadas por el PRN, sufrieron fuertes impactos en su calidad de vida derivados de la segregación de sus redes y relaciones de origen y la no pertinencia de sus viviendas en relación con sus modos de vida, lo que relativiza en gran parte la evaluación positiva del impacto social del Programa.

\subsection{Segunda Etapa: Fase de Renovación Urbana Desregulada Post Ribera Norte (2007-2015). El Puente Chacabuco y la catástrofe como detonantes del proceso de desplazamiento de Aurora de Chile}

La segunda parte del proceso de renovación urbana posterior al PRN es más difusa y ya no obedece a una planificación público-privada articulada en torno a una gobernanza clara y a un diseño con información pública, sino más bien a una agudización de la hegemonía de la lógica privada, esta vez sin un liderazgo público que coordine las múltiples iniciativas proyectadas por Ribera Norte para el sector. Esta fase de renovación urbana desregulada, retoma la presión sobre el área céntrica de la Costanera previamente priorizada por Ribera Norte como "proyecto detonante" haciéndose cargo del fuerte déficit de inversión privada en ese estratégico sector. Ante esto, el Estado se ve obligado a dar nuevas garantías para fomentar el interés empresarial en el área, ya que su participación se vio entorpecida por problemas de conectividad (línea férrea), restricciones normativas y por la poca seguridad respecto a los terrenos usados por la Población Aurora de Chile. (Entrevista Bernardo Suazo, ex director Plan Ribera Norte, octubre 2015).

El re-impulso del proyecto de renovación urbana va a estar dado por la liberalización de normativas de usos de suelo. Esta es decisiva para permitir que la Costanera se convierta en un "producto atractivo" para la inversión privada, reduciendo los precios, liberalizando su accionar para atraer los recursos que permitan desarrollar el proyecto y así lograr sus objetivos iniciales (Cociña et al. 2006). El instrumento elegido para esto es la modificación del Plan Seccional Ribera Norte (2006 y 2009), que libera los coeficientes de constructibilidad y de ocupación de suelo, creando zonas especiales para la construcción en altura, alternando usos comerciales y residenciales. En definitiva, el Estado facilita e incentiva el actuar del privado, haciendo cambios en la regulación del territorio, para promover sus intereses mediante grandes inversiones urbanas, justificadas por medio de discursos que apelan al desarrollo y a cumplir el "deseo de la ciudad" de recuperar su relación con el borde río, posicionando al sector privado como el único actor capaz de concretar ese sueño urbano.

El año 2010 la ciudad de Concepción fue sacudida por uno de los sismos de mayor magnitud de los últimos cincuenta años, causando cerca de 140 muertos en la región del Biobío (Subsecretaría del Interior de Chile, 2011). Este evento sísmico además de provocar fuertes desastres humanos y materiales, fue utilizado como una oportunidad política y económica aprovechando el estado de crisis o de shock post-catástrofe (Klein, 2007), para justificar la finalización e inicio de proyectos urbanos que no se habían logrado concretar hasta la fecha en el espacio céntrico de la ribera norte del Biobío. El Puente Chacabuco, obra proyectada en el Plan Regulador Metropolitano (2002) para ser construida en forma posterior a la construcción del Puente Industrial, es re-jerarquizado como proyecto emblemático de "reconstrucción" que reemplaza el Puente Viejo, que se ve fuertemente afectado por el Terremoto.

Aprovechando el contexto de "crisis urbana" que genera la catástrofe, el terremoto ofrece la justificación necesaria para impulsar una obra de infraestructura que aporte a reactivar el área estratégica no desarrollada por privados que estaba pendiente desde Ribera Norte, y que forma parte central de la ampliación del sistema de transporte regional. La noción del "bien común" que encarna esta infraestructura, se instala rápidamente en el discurso público como la única 
solución a la falta de conectividad generada por el evento sísmico. El antiguo ideal urbano de "conquistar la Costanera para la ciudad" de Concepción, es utilizado para construir un sentido común que ayude a legitimar la construcción.

“Empresarios, inmobiliarias, inversionistas, cada quien con su visión del uso del borde costero del Biobío, frente a la ciudad, en un proyecto de larga data que tiene por objeto que ésta deje de darle la espalda al río, y le acepte como un recurso de valor inestimable tanto en lo paisajístico como desde la óptica del desarrollo urbano. Crear para Concepción una nueva postal."(Editorial Diario Concepción 28-03-2014)

Por otro lado, el nuevo ideario metropolitano de "ciudad extendida", se legitima y cobra relevancia como argumento el que la "reconstrucción de la región", sea liderada por una infraestructura emblemática que acelera la conectividad inter-comunal. Es así como el Alcalde de San Pedro manifiesta públicamente su adhesión al proyecto, indicando que el Puente será fundamental para el crecimiento y el desarrollo inmobiliario del sector de Idahue. La visión del edil contrasta con la del Alcalde de Concepción, quien en un primer momento resta apoyo a la decisión de impulsar la obra, apelando a la mala gestión en la realización de la obra y al nulo acercamiento que sus impulsores tuvieron con la población afectada.

La articulación entre la construcción del Puente y la implementación de proyectos inmobiliarios, se hace evidente al revisar la prensa de Concepción. Un primer hito lo plantea el desarrollo del abortado proyecto Terrazas del Biobío, declarado el año 2010 como proyecto de interés público. Posteriormente, los medios asociarán la construcción del puente como un hito de conectividad, que aporta a la consolidación del desarrollo inmobiliario del sector Costanera. En ese marco el discurso de empresas inmobiliarias como Aitué y Futuro revela su visión del territorio como una "zona natural de expansión", que destaca por su gran conectividad, proximidad al barrio cívico y al Puente Bicentenario.

El puente ayuda a consolidar una puesta en valor de Costanera que va más allá de la centralidad tradicional, re-escalando el interés inmobiliario a un nivel inter-comunal. En efecto, ya a fines del 2014 se hacen evidentes en la prensa los efectos positivos en términos de valoración de los terrenos, no solo de la Ribera Norte (Concepción), sino de la Ribera Sur (San Pedro). Al respecto se cita la importante activación de inversiones privadas expresada en los proyectos de las inmobiliarias Pocuro (Idahue) y Domus (Parque Millaray).

En contraste, el inicio del conflicto urbano se remonta a la frustrada tentativa de desplazamiento que plantea el caso de los "falsos terremoteados" ${ }^{4}$, intento que genera como reacción la activación política en la población. En ese contexto un grupo de pobladores crea el Movimiento Cultural Pro Defensa y Cultura Aurora de Chile (MC), que adopta prácticas de organización política orientadas a la "agitación de los pobladores", la visibilización del conflicto a través del uso de los espacios públicos de la población y de la ciudad, junto con la articulación con actores territoriales que viven conflictos similares ligados a la Red Construyamos, que agrupó a vecinos de Villa Futuro, Centinela y otras poblaciones (Fig. 3). Es así como durante el periodo 2012-2014 el MC lidera marchas, actos culturales, asambleas, boletines informativos y murales, complementados por una estrategia comunicacional que utilizó como principal vía de difusión al periódico electrónico Resumen, donde se posicionó una

4 En Septiembre de 2010, la Intendenta Van Rysselberghe, con la venia de la Municipalidad, declara la falsa inhabitabilidad de las viviendas de Aurora con el objetivo de que la población abandone el terreno, utilizando el mismo modus operandi que utilizó con Centinela, Villa Futuro y Olavarría, planteando beneficios para que dejaran sus casas y se hiciera pasar por "falsos terremoteados". 
visión crítica al conflicto apelando al "derecho a la ciudad" y denunciando el accionar privatizador y gentrificador del Estado.

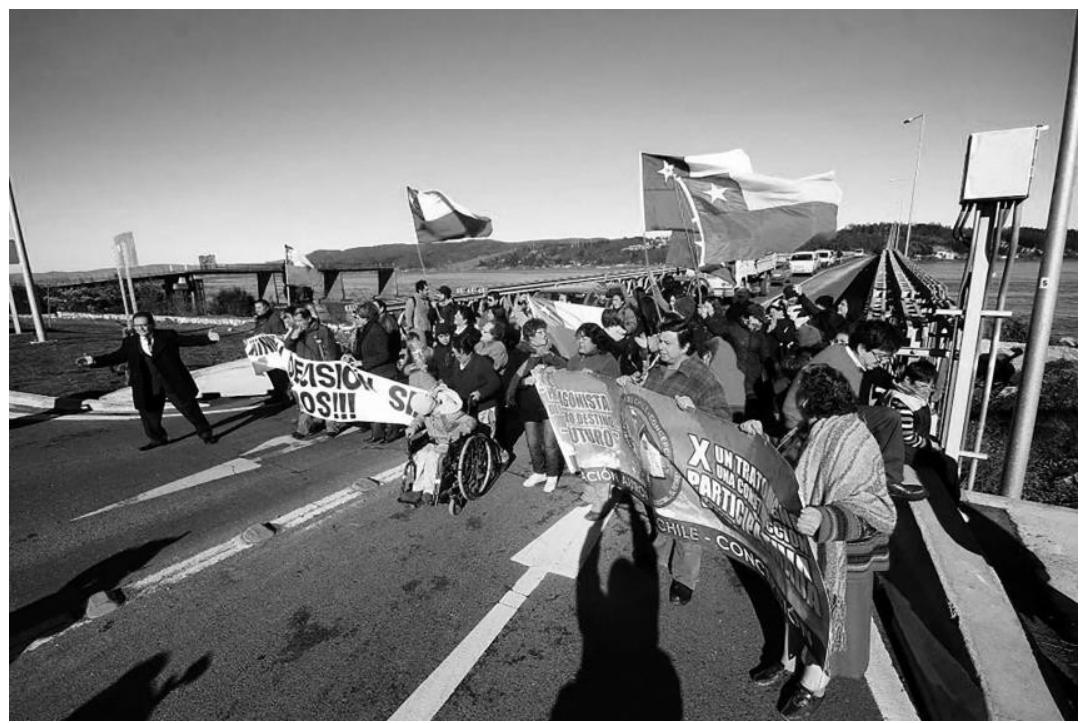

Fig. 3 Manifestación pobladores Aurora de Chile, toma Puente Chacabuco (2012) Fuente: Fotografía Carlos Rodríguez

Finalmente, ante el retraso en la finalización del Puente, producto de la negativa de los pobladores de abandonar su hábitat histórico, el Estado chileno, bajo el segundo gobierno de Bachelet, se ve obligado a cambiar su estrategia de trabajo con la población. EI MINVU crea un equipo social adscrito al programa Quiero Mi Barrio que desarrolla un primer catastro de viviendas y habitantes de Aurora (enero de 2015) el que constituye la base para lo que se conocerá como el Plan Integral Aurora de Chile (MINVU 2015), que es definido como una herramienta de "regeneración urbana" que propone a los pobladores una serie de beneficios especiales ${ }^{5}$ para acceder a vivienda.

Si bien el "Plan Aurora" apela a la noción de planificación integrada propia del discurso técnicoparticipativo que adopta actualmente la planificación nacional, en la práctica constituye una estrategia de erradicación, directa para las familias que viven en la franja del puente, y de erradicación indirecta para todas aquellas que quieran beneficiarse del "sueño de la casa propia". Su ejecución propone tres etapas, las dos primeras tienen como prioridad despejar la faja de afectación del Puente Chacabuco. La fase I, actualmente en construcción, considera la erradicación directa de 193 familias al proyecto CNT Angol, ubicado en el humedal Chepe, costado poniente de la Costanera y que reunirá a pobladores de Aurora con otros pobladores desplazados por el terremoto pertenecientes a Villa Futuro. La fase II, actualmente en elaboración de proyecto, contempla la reubicación en terrenos semi-baldíos ubicados a un costado del Parque Bicentenario, que movilizará a 206 familias históricas. La tercera fase, proyectada para ejecutarse después de la construcción del segundo tramo del puente (2018) contempla a las cerca de 200 familias restantes, incorporando la reurbanización de todo el sector.

5 EI MINVU flexibiliza los mecanismos de postulación regular para obtener vivienda social, ofreciendo la asignación del beneficio sin concurso, sin puntaje en la Ficha de Protección Social, sin ahorro previo, ni las excepciones exigidas por el D.S.49, sin deuda, permitiendo acceder a viviendas con más metros cuadrados (hasta $63 \mathrm{~m} 2$ ), y con mejor materialidad de terminaciones (Minvu 2015). 
Es relevante señalar que el enfoque del MINVU está basado en reducir la problemática de la población a un tema habitacional, dejando de lado la inclusión en el proyecto de "regeneración" los aspectos históricos y simbólicos que dan identidad a Aurora como comunidad (CEDEUS, 2015). El plan promueve el desplazamiento no solo mediante la expulsión directa de un tercio de la comunidad, sino que en forma indirecta al modificar el estilo de vida histórico de la población radicada homogeneizando su espacio residencial y público al patrón general de otros barrios de renovación urbana ofertados a sectores medios.

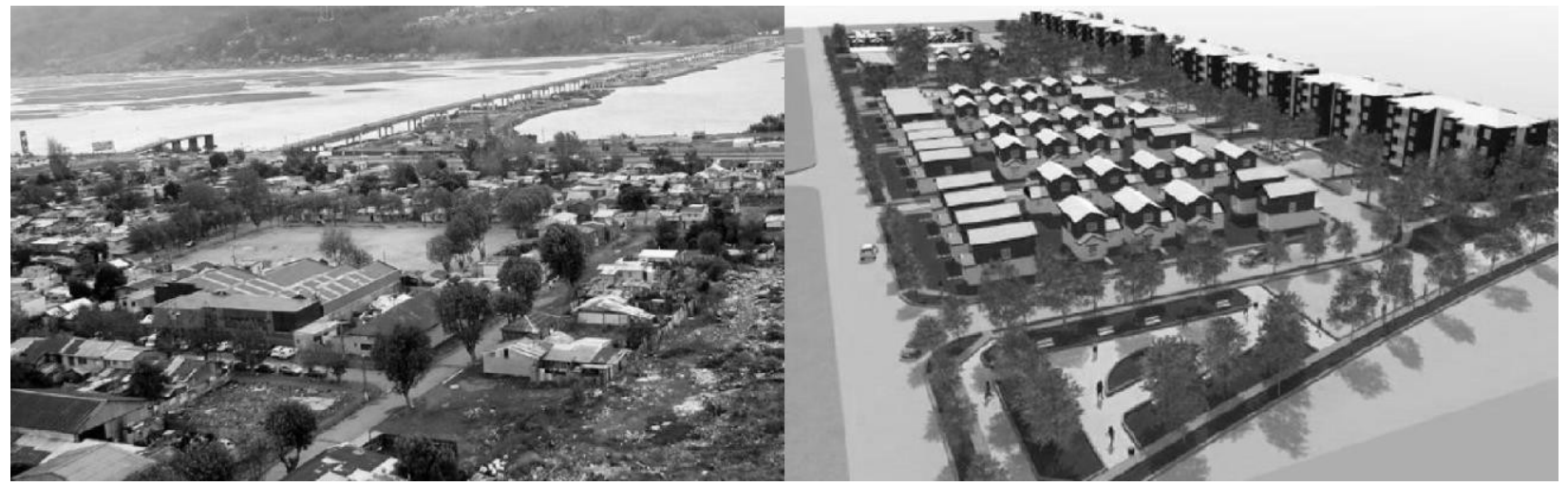

Fig. 4 Fotografía Población Aurora actual e imagen objetivo Aurora post radicación (2017) Fuente: elaboración propia en base a material MINVU (2016)

La imagen propuesta para la radicación se encuentra asociada claramente a una estética aspiracional similar a la oferta de los nuevos condominios de clase media que promueve la publicidad inmobiliaria en Concepción (Fig. 5). Es en el plano de los efectos socio-territoriales que plantea el cambio forzado de estilos de vida, que se pueden vislumbrar los impactos que generará en términos de la fragmentación de la comunidad la transformación de un territorio, que favorece la sociabilidad y el desarrollo de economías familiares, en un "nuevo barrio de renovación urbana". En ese marco es posible proyectar efectos gentrificadores asociados al encarecimiento abrupto del costo de vida, y a la dificultad de adaptación espacial a una nueva dinámica de relaciones más constreñida en el espacio. Esto, dada la alta rentabilidad del suelo urbano de Costanera, puede generar un incentivo para la venta o arriendo de sus viviendas en el mediano plazo, considerando que estas seguirán aumentando su valor, a medida que se profundiza el proceso de renovación del sector, provocando - probablemente- un proceso de recambio de población originaria por nueva población de sectores medios.

Finalmente, el impacto catalizador sobre el proceso de renovación urbana de Costanera que plantea la finalización del Puente, se hace evidente y determina también un cambio de paisaje urbano que consolida el futuro aislamiento de Aurora de Chile en la Costanera (Fig. 6). A los proyectos de urbanización e infraestructura ejecutados previamente en el período de Ribera Norte (Avenida Costanera, Puente Llacolén y Avenida Padre Hurtado), se suman post terremoto, un conjunto de proyectos de escala comunal como la construcción del Parque Bicentenario, del Mall Mirador y la ejecución del tramo del Puente Chacabuco que conecta San Pedro con la zona norte de Concepción. Actualmente, ratificado el desplazamiento de los pobladores, se anuncia la ejecución de proyectos como el Teatro Regional del Biobío (en construcción), la sede de la PDI, un proyecto de torres inmobiliarias sumados al diseño futuro de la Biblioteca Regional y el Museo de la Memoria para ser emplazada en el entorno del sector centro de la Costanera. 


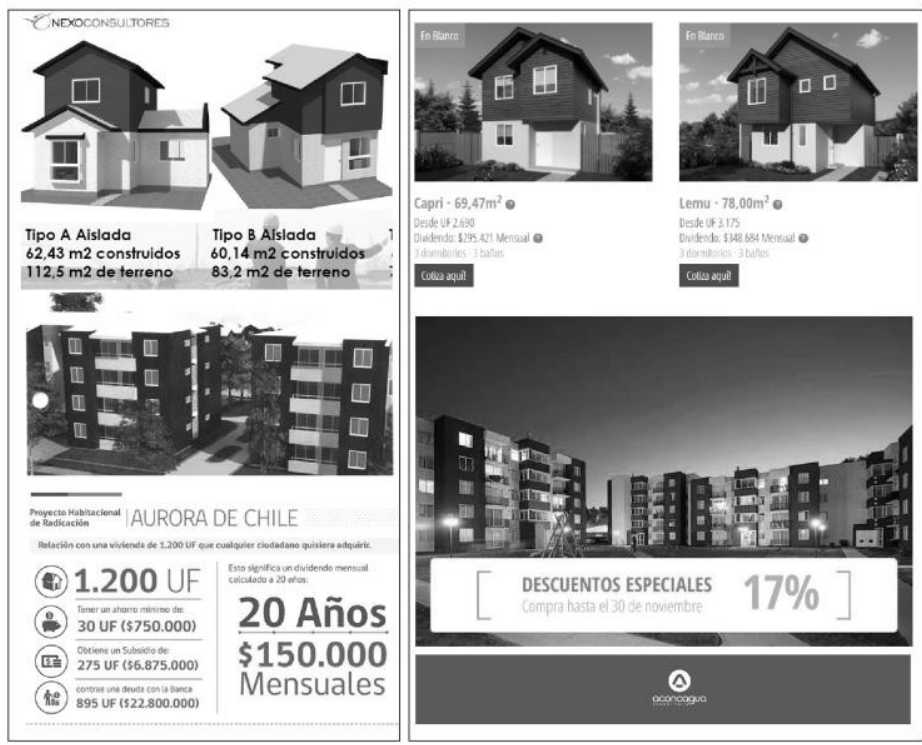

Fig. 5 Comparación prototipos de vivienda Plan Aurora de Chile (fase II radicación) con oferta inmobiliaria para sectores medios en Concepción

Fuente: elaboración propia en base a Minvu y publicidad Inmobiliaria Aconcagua

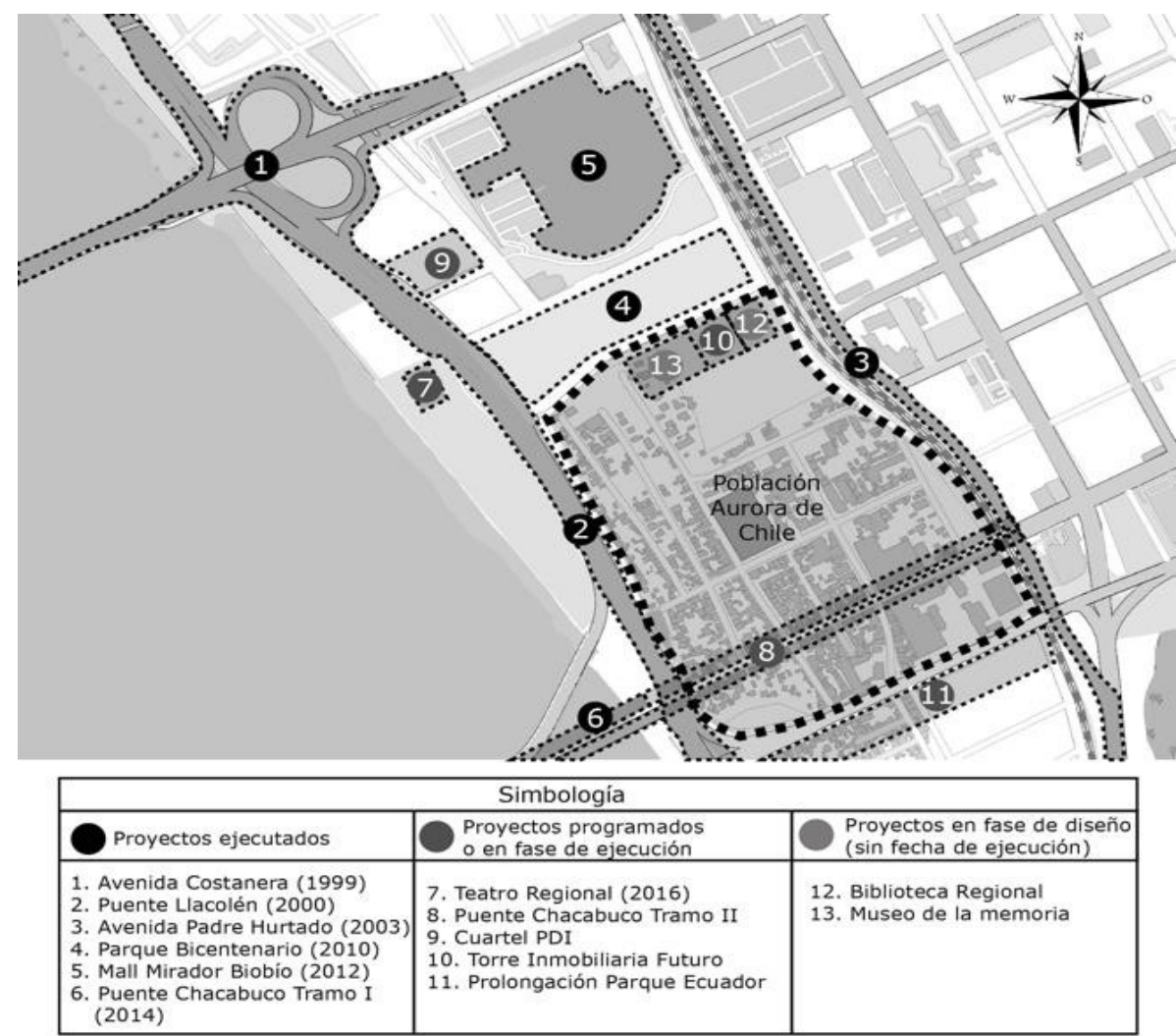

Fig. 6 Proyectos y obras programadas en el entorno de la Población Aurora de Chile (2006- 2015) Fuente: elaboración propia 


\section{La construcción simbólica sobre el desplazamiento post-catástrofe: entre la "naturalización", la negociación y la resistencia}

La revisión de prensa realizada establece la existencia de dos variantes discursivas sobre la renovación urbana de la Costanera, donde se emplaza la Población Aurora de Chile. Por un lado, discursos y representaciones que articulan la renovación urbana con la necesidad de desplazamiento de población; y por otro representaciones, lideradas por la actual gestión regional del MINVU que plantean la posibilidad de una renovación urbana asociada al discurso más contemporáneo de una planificación participativa que encubre el desplazamiento a partir de presentar una "solución integral" para la Población Aurora de Chile.

En el primer caso se trata del discurso expresado en la prensa por urbanistas y técnicos que se ve respaldado por las editoriales de los periódicos regionales, particularmente por las del Diario Concepción. Este configura un punto de vista que naturaliza la visión de que la población constituye un obstáculo al progreso, una externalidad negativa que debe ser superada. Ante el complejo escenario, diversas voces del sector privado hacen presión mediática al sector público para acelerar una rápida solución al conflicto de Aurora de Chile (Fig. 7).

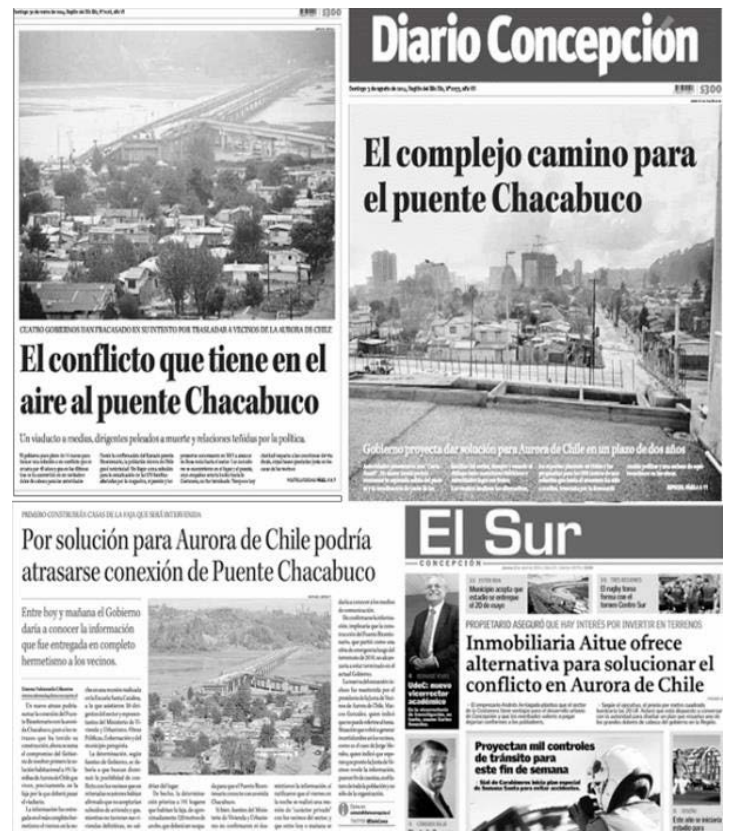

Fig. 7 Síntesis titulares de prensa referentes al conflicto del Puente Chacabuco (2013-2014) Fuente: elaboración propia

A la visión de los privados, que prevalece en el discurso de la prensa, se suma la mirada de los planificadores que participaron en el PRN y que repone el uso de la "idea del bien común", al contraponer el derecho de los pobladores a permanecer en su territorio, con el derecho al desarrollo de "toda la ciudad".

“...creo que la ciudad y el resto de los habitantes también tienen derechos digamos... y no puede existir un grupo de personas que cierren un lugar (...) en general yo creo que uno se puede identificar con su barrio, pero no puedes apropiarte del barrio... 
porque la ciudad es una sola... porque si no deja de ser democrática en definitiva" (Bernardo Suazo, ex director Ribera Norte, entrevista semi-estructurada, 2015)

Por otra parte, la prensa local y los urbanistas, comienzan a recoger la necesidad de una mayor participación de los pobladores, instalando discursos sobre la necesidad de hacerse cargo, desde una perspectiva de planificación integrada, de la "solución" al conflicto de Aurora de Chile.

Este cambio de tono, es representativo del discurso de las nuevas autoridades cuando se produce el cambio de gobierno de Piñera a Bachelet. Retomando el "espíritu" de un idealizado PRN, se plantea la disposición a realizar un proceso de radicación/erradicación participativo. En efecto, la política pública hace un giro discursivo y reconoce como déficit de la estrategia de renovación, la falta de una mayor inclusión del punto de vista de los pobladores, no obstante, siempre dentro de la decisión de acelerar la construcción del puente:

"Nos estamos haciendo cargo. Nos inspira hoy en Aurora de Chile llevar adelante un trabajo que tenga la densidad en planificación y participación como lo tuvo el programa Ribera Norte, que dio respuesta, en una primera entrada, al requerimiento histórico que ha tenido Concepción de llegar al río y que permitió que gran parte de las familias que por años han vivido en el sector lo sigan haciendo. Eso lo queremos replicar en Aurora de Chile", recalcó el seremi de Vivienda y Urbanismo, Jaime Arévalo." (Especial Aurora de Chile, Reportaje Diario Concepción, 03-08-2014)

Una vez que se hace irreversible la construcción del puente, la prensa y los tomadores de decisiones dan cuenta de los nuevos desafíos socio-técnicos para lograr "mayor justicia y menores daños", en un contradictorio y posmoderno doble discurso que, apelando al diálogo y la participación, tiende a justificar de una forma más sofisticada, el desplazamiento del modo de vida del poblador, por el beneficio de la ciudad.

"Es posible que hayan daños colaterales, pero eso no es barrera insalvable si se toman las medidas que correspondan para la mejor justicia y el menos daño. Al final, tiene que haber un saldo positivo al considerar el impacto favorable de este puente, como fue concebido, para el desarrollo de la región" (Prensa editorial, Diario Concepción, 27-07-2014)

En contraposición, los discursos de los pobladores respecto al conflicto, transitan entre dos lógicas. Por un lado, una lógica de resistencia territorial al desarrollo urbano centrada en reivindicar su legitimidad histórica como primeros habitantes y urbanizadores de la Costanera, y por otra, una lógica de negociación que aspira a un mejor trato, reconociendo fácticamente el proceso de desplazamiento y erradicación. En este contexto dos organizaciones expresan estas lógicas diferenciales. Por un lado el ya citado MC, que se crea como primera reacción a la construcción del puente para posicionar una postura más radical de resistencia dentro y fuera de la población, y por otro la Junta de Vecinos en tanto la voz formal que dialoga a partir de 2014 directamente con el Estado.

EI MC cumple un rol de activar la resistencia territorial a la imposición del Puente, denunciando un desplazamiento forzado planteando un discurso que interpela directamente al modelo de desarrollo neoliberal y contraponiendo al predominio del valor de uso la re-apropiación del valor de uso, asociado a la construcción histórica del territorio realizada por los pobladores:

"Nos hemos organizado con el objetivo de defender nuestro territorio frente a un nuevo intento de las Inmobiliarias, el Estado y sus autoridades políticas por despojarnos de nuestros terrenos. Por delante tenemos dos tareas urgentes: 
demandar al Estado de Chile el reconocimiento de la propiedad de nuestros vecinos sobre su suelo y, segundo, detener la construcción del puente Chacabuco, en tanto este no contempla a nuestra población en su diseño y ejecución.(...) Aquí crecimos y construimos una vida entera. Somos conscientes del valor de nuestro suelo, allí está el motivo de este nuevo intento para expulsarnos (...) Decimos a las autoridades que el Puente Chacabuco será sólo un nuevo intento frustrado por despojarnos". (Extracto de declaración Pública Movimiento Cultural, mayo 2013)

No obstante, el discurso inicial de resistencia territorial da un giro hacia uno de negociación con el Estado. En ese marco la influencia del MC tiende a desaparecer, entregando protagonismo al discurso de los pobladores agrupados en base al espacio institucional de la Junta de Vecinos. Esta, en su lógica de acción, junto con tensionar las relaciones con las autoridades, rechazando inicialmente las soluciones propuestas, manifiesta estar dispuesta a ceder y participar de un plan de radicación que les dé mayor participación y reconocimiento por parte de la ciudad, presentando observaciones a la propuesta de gobierno:

“...es un logro gigantesco presentar un documento, nosotros pudimos dar una contra propuesta en donde expusimos unas bases para poder empezar a trabajar y una de las bases lógicas es que se respete la historia (...) yo pienso que (...) lo que no se puede transar con esta propuesta, son los terrenos (...) ellos vienen a imponer un decreto 49 que no tiene ningún sentido (...) entonces en eso estamos tratando de llegar a un acuerdo, que estas cosas no se pueden hacer de la noche a la mañana hay que estarlas paso a paso viendo que no se de un paso en falso o que se cometa algún error que pueda ser grave pa nuestra gente". (Priscila Hernández, Vocera de la Junta de Vecinos, entrevista semi-estructurada, septiembre 2015)

En el marco de la negociación los dirigentes vecinales vuelven a "naturalizar" su desplazamiento como un hecho irreversible, construyendo un relato que articula resistencia con negociación en base a lo posible, develando las tensiones no resueltas de sus tácticas y estrategias para enfrentar el conflicto y generando una dinámica donde los discursos de reivindicación del derecho a su permanencia histórica en la Costanera, propios de una "ciudadanía insurgente" (Holston, 2009), coexisten con su búsqueda de un "nuevo trato" o de una "solución que plantee una vivienda digna", generándose una práctica política híbrida configurada en base a una autonomía que es siempre relacional (Russell \& Tokliatán, 2003) marcada por un sentido de respeto a un Estado que aún sigue siendo visualizado, a pesar de sus prácticas desplazadoras, como un ente garante del bien común.

\section{Conclusiones}

En el marco de la expansión y consolidación de un modelo de desarrollo urbano de corte neoliberal, el caso Aurora de Chile entrega evidencia respecto de cómo un desastre natural y la consecuente gestión política de proyectos y programas de reconstrucción, configuran un contexto estratégico de oportunidad para acelerar procesos de renovación urbana y desplazamiento que se encontraban congelados hace más de 10 años en la zona céntrica de la Costanera de Concepción; los que se reactivan, en una escala más amplia, a partir del reimpulso que le otorga la construcción de una mega-obra de infraestructura de transporte metropolitano y regional.

Autores como Harvey (2008) plantean que las intervenciones que se generan en las grandes ciudades, fundamentalmente aquellas asociadas con dinámicas de renovación urbana (infraestructura de transporte o desarrollos inmobiliarios importantes), constituyen los principales detonadores a través de los cuales las ciudades sostienen la absorción de 
excedentes de capital. Para dichos efectos, la actual gestión neoliberal y desregulada de las ciudades, viene generando el despliegue de modalidades específicas de gobernanza, donde confluyen simbióticamente los intereses del Estado con el de desarrolladores privados, con el objeto de que dicho excedente incremente la ganancia de las corporaciones privadas, en lugar de distribuir de modo justo y equitativo el bienestar; el acceso universal a bienes y servicios; y el desarrollo urbano en todas sus escalas para los habitantes de la ciudad.

Bajo esta actual institucionalidad de corte gerencialista, la participación de la comunidad y la ciudadanía queda notablemente descolocada del juego de incidencias y protagonismos; y el Estado deja de constituirse en un agente que garantiza y provee directamente el acceso universal a determinados bienes y servicios, para desplegarse ahora como agente que dinamiza los mercados y arbitra entre desarrolladores privados, cuyo marco de acción se circunscribe a la regulación, negociación y monitoreo de contratos con agentes particulares para la provisión de servicios públicos.

Así, mientras más se expande la ciudad y la urbanización desregulada, más se promueve su valor de cambio, y se vivencia la degradación de los vínculos sociales, comprimiendo y desarticulando en el espacio las sociabilidades populares, hecho que se hace evidente en los procesos de expulsión y desplazamiento de poblaciones precarizadas.

El análisis de caso permitió distinguir efectos socio-espaciales que respaldan la hipótesis del uso de renovación urbana como una estrategia política global -manifiesta o latente- de elitización del espacio urbano; fuertemente liderada por intereses privados. En primer lugar, el desplazamiento directo e indirecto de pobladores de Pedro del Río y Aurora, como efecto del Plan Ribera Norte y sus proyectos de radicación. Asimismo, destaca el proceso de desplazamiento en curso que plantea la propia construcción y empalme del Puente Chacabuco, atravesando directamente por el corazón del territorio de Aurora de Chile; y detonando una serie de iniciativas e inversiones múltiples de impronta público-privada (mall, soterramiento línea del tren, teatro regional, parque Bicentenario, edificios públicos, etc.). En particular, planteamos la necesidad de indagar los impactos socio-culturales que tendrá el nuevo proceso de radicación/erradicación, estableciendo probablemente un punto de no retorno en el modo de vida de una población histórica como Aurora de Chile, determinando la supresión del uso social del espacio y su escala barrial; dando luz verde a un modo de vida metropolitano que no está siendo regulado y gestionado por la planificación urbana, sino fácticamente por la articulación hegemónica de actores público-sectoriales (obras públicas-transporte) y consorcios privados con importante presencia y trayectorias de inversión en la región.

En segundo lugar, el análisis del proceso de renovación post-catástrofe visibilizó el efecto de "naturalización del bien común" como relato que justifica la intensificación de políticas globales de gentrificación urbana de carácter expulsivas. Se trata de una estrategia de legitimación discursiva del proceso de renovación urbana, donde se logra crear sentido común en una gran heterogeneidad de grupos sociales (gran parte de la opinión pública, parte de urbanistas y en parte del discurso de los propios desplazados). De la mano de la naturalización del discurso del bien común, se desprenden efectos de estigmatización del valor de uso de los sectores populares y promoción de la sustitución de sus prácticas espaciales, económicas y sociales, por los patrones de consumo del suelo urbano asociados a los emergentes estilos de vida "céntricos" y "metropolitanos"- que promueve una renovación urbana "en altura", dirigida a saciar la demanda de los emergentes sectores medios y medios alto, que poblarán las nuevas urbanizaciones situadas en el entorno de la Costanera tanto en Concepción como en San Pedro.

De este modo, planteamos que las dinámicas de renovación y recualificación urbana implican en la mayoría de los casos- desalojo de historias, ocupantes del territorio, paisajes, usos, etc., 
y tienen como objeto central desplazar a sujetos "indeseables" bajo diversos pretextos plagados de buenas intenciones, como la revitalización de zonas degradadas y abandonadas; la recuperación del centro histórico; el progreso de la ciudad; el bien común, etc. Estos contenidos se utilizan como argumentos discursivos neutrales para expulsar a diversos tipos de habitantes, particularmente a los llamados "ciudadanos parciales" (Appadurai y Stenou, 2001).

El estudio revela cómo el urbanismo neoliberal genera un efecto institucional devastador a nivel de los actores que debieran hacerse cargo de regular los abusos de las políticas de renovación urbana. En ese sentido, la actual propuesta de radicación desmiente los avances que plantearía para la planificación urbana el establecimiento de la Política Nacional de Desarrollo Urbano (2014), des-dibujándose el rol protagónico del Estado en la construcción de ciudad, y haciéndose más evidente el ethos neoliberal que caracteriza a la gestión urbana bajo una lógica de "destrucción creativa" (Theodore, Peck \& Brenner, 2009), donde destaca el Puente Chacabuco en nuestro caso de estudio.

La expansión e intensificación de los patrones de desregulación contrasta con una posmoderna gramática de inclusión social, participación, equidad urbana y democratización de la ciudad expresada en las orientaciones de la nueva Política Nacional de Desarrollo Urbano; que apela a revitalizar su tradicional opción por lo público a partir del re-conocimiento y la necesidad de avanzar hacia un modelo socio-técnico menos disperso de planes y proyectos, con enunciados que pretenden encaminarse hacia un horizonte de planificación integrada, participativa, intersectorial y colaborativa para nuestras ciudades.

Finalmente, a esta tendencia se suma la ausencia de los municipios (Concepción y San Pedro de la Paz) involucrados en el impacto y costo social de las dinámicas antes expuestas, que en general no han actuado como gobiernos locales mandatados por sus electores y al servicio de los grupos más desfavorecidos y precarizados espacialmente, sino como promotores inmobiliarios que facilitan la generación de mayor plusvalía asociada con los futuros proyectos a ambos lados del río, destacando la falta de una visión que reponga el valor de lo público por sobre la hegemonía del valor de cambio (Lefebvre, 1969), en una Costanera que después del desastre deviene en un renovado "espacio de deseo" inter-escalar (barrio, comuna, metrópolis, región); desconociendo las condiciones estructurales de la desigualdad socio-territorial de nuestras ciudades.

\section{Referencias}

Appadurai, A. \& Stenou, K. (2001). El pluralismo sostenible y el futuro de la pertenencia. En Centro Unesco Montevideo (Ed.), Informe Mundial sobre Cultura 2000-2001. Diversidad cultural, conflicto y pluralismo. Recuperado http://132.248.35.1/cultura/informe/informe\%20mund2/Cap\% C3\% AD7.htm

Aricó, G., Mansilla, J., \& Luca, M. (2015). Mierda de ciudad. Una rearticulación crítica del urbanismo neoliberal desde las Ciencias Sociales (1a edición). Barcelona: Editorial Pol·len edicions.

Audefroy, J. \& Ottolini, C. (Coords.) (1999). Vivir en los centros históricos. Experiencias y luchas de los habitantes para permanecer en los centros históricos. Ciudad de México: Hábitat Internacional Coalition, Most. 
Bascur, H. (2006). Satisfacción residencial y capital social en el Programa Ribera Norte. Revista del Centro de Investigación Social de Un Techo para Chile, 5(7), 44-59. Recuperado de http://www.techo.org/paises/chile/wp-content/uploads/2016/08/CIS7-10-Satisfaccionresidencial.pdf

Brenner, N. \& Theodore, N. (2005). Neoliberalism and the urban condition. City, 9(1), 101-107. https://doi.org/10.1080/13604810500092106

Centro de Desarrollo Urbano Sustentable, CEDEUS. (2015). Bases Fundamentales para un proyecto integral para Aurora de Chile. Documento de Trabajo. Santiago de Chile: Autor.

Cociña, C., Klenner, M., Lira, I., Sellés, J., y Valenzuela, N. (2006). Proyecto Ribera Norte. Recuperado de http://bit.ly/19l rgYM

Davidson, M. \& Leeds, L. (2010). New-build gentrification: Its histories, trajectories, and critical geographies. Population Space and Place, 16, 395-411. https://doi.org/10.1002/psp.584

Delgadillo, V. (2015). Desafíos para los estudios de desplazamientos sociales en los procesos de gentrificación. Documento presentando en Contested Cities, WPCC 15002.

Fainstein, S. (1994). The City Builders. Property, Politics \& Planning in London and New York. Oxford: Blackwell.

Fals Borda, O. (2007). La investigación acción en convergencias disciplinarias. Forum, 38, 17-22. Recuperado de https://lasa.international. pitt.edu/forum/files/vol38/LASAForum-Vol38-Issue4.pdf

Fernández, E. (2015). El territorio y su construcción imaginaria social. La experiencia de la Población Aurora de Chile (Tesis de Sociología). Universidad de Concepción, Concepción, Chile.

Ferrada, C. (2011). Reconstrucción histórica de la población Aurora de Chile a partir de una geografía familiar (Tesis de Sociología). Universidad de Concepción, Concepción, Chile.

Flores, S. (2013). Programa de recuperación urbana Ribera Norte Concepción. Análisis a veinte años de su puesta en marcha (Seminario de Título Arquitectura). Universidad del Biobío, Biobío, Chile.

Janoschka, M. y Sequera, J. (2014). Procesos de gentrificación y desplazamiento en América Latina. Una perspectiva comparativista. En J. J. Michelini (Ed.), Desafíos metropolitanos. Un diálogo entre Europa y América Latina (pp. 82-104). Madrid: Catarata. Recuperado de http://contestedcities.net/wp-content/uploads/2014/07/2014CC_Janoschka_Sequera_Desplazamiento_AL.pdf

Harvey, D. (2008). The right to the city. New Left Review, 53. Recuperado de https://newleftreview.org/l1/53/david-harvey-the-right-to-the-city

Harvey, D. (1989). From managerialism to entrepreneurialism: The transformation in urban governance in late capitalism. Geografiska Annaler. Series B, Human Geography, 71(1), 3-17,

Hidalgo, R. y Janoschka, M. (Eds.) (2014). La ciudad neoliberal. Gentrificación y exclusión en Santiago de Chile, Buenos Aires, Ciudad de México y Madrid (1era Edición). Santiago de Chile: Instituto de Geografía, Pontificia Universidad Católica de Chile. 
Holston, J. (2009). La ciudadanía insurgente en una era de periferias urbanas globales: un estudio sobre la innovación democrática, la violencia y la justicia social. En G. Delamata (Ed.), Movilizaciones sociales: ¿nuevas ciudadanías? Reclamos, derechos, estado en Argentina, Bolivia y Brasil (pp. 46-65). Buenos Aires: Biblos.

Inzulza-Contardo, J. (March, 2014). Gentrification in the context of post-earthquake reconstruction urban policies: A review of the Chilean experience Global Urban Research Centre Working Paper 9. Manchester: The Global Urban Research Centre (GURC), University of Manchester.

Inzulza-Contardo, J. (2012). 'Latino-Gentrificación'? Focusing on physical and socioeconomic patterns of change in Latin American inner cities. Urban Studies, 49(10), 2085-2107. https://doi.org/10.1177/0042098011423425

Insulza-Contardo, J. y López, N. (2014). Gentrificación de escala intermedia global en Latinoamérica: el caso de la reconstrucción de Managua, Nicaragua 1972-2014. Revista de Urbanismo, 31. https://doi.org/10.5354/0717-5051.2014.33274

Klein, N. (2007). La doctrina del Shock. El auge del capitalismo del desastre (1a edición). Buenos Aires: Paidós.

Lasalle, A. y Cabrera, C. (2000). Memorias a orillas del Biobío (1a edición). Concepción: Siegfried Obrist.

Lefebvre, H. (1975). El derecho a la ciudad (3a edición). Barcelona: Ediciones Península.

Letelier, F. y Boyco, P. (2013). Talca a tres años del terremoto: aprendizajes colectivos para la acción en la ciudad. Temas Sociales, 70. Recuperado de http://surmaule.cl/temas-sociales-no-70-talcaa-3-anos-del-terremoto/

Marcuse, P. (1985). Gentrification, abandonment and displacement: Connections, causes and policy responses in New York City. Journal of Urban and Contemporary, 28, 195-240. Recuperado de http://openscholarship.wustl.edu/cgi/viewcontent.cgi?article=1396\&context=law_urbanlaw

Ministerio de Vivienda y Urbanismo, Minvu (2001). Ribera Norte Concepción de cara al Bío-Bío. Concepción: Autor.

Ministerio de Vivienda y Urbanismo, Minvu. (2015). Catastro Población Aurora de Chile. Concepción: Autor.

Ministerio de Vivienda y Urbanismo, Minvu. (2015). Plan Integral Aurora de Chile. Concepción: Autor.

Mitchell, D. (2003). The right to the city. Social justice and the fight for public space. New York: The Guilford Press.

Olguín, R. (2011). Experiencias, visiones y relatos sobre la geografía de la vida cotidiana en la población Aurora de Chile de Concepción (Tesis de Pregrado de la Carrera de Sociología), Universidad de Concepción, Concepción, Chile.

Ong, A. (2006). A mutations in citizenship. Theory, Culture \& Society, 23(2-3), 499-531. https://doi.org/10.1177/0263276406064831 
Ottolini, C. y Berger, C. (1999). Estrategias populares en los centros históricos. Padova: HIC, Unione Inquilini, Habitat et Participation.

Paulsen, A. (2014). Negocios inmobiliarios, cambio socioespacial y contestación ciudadana en Santiago Poniente. El caso del barrio Yungay: 2000-2013. En R. Hidalgo y M. Janoschka (Eds.), La ciudad neoliberal. Gentrificación y exclusión en Santiago de Chile, Buenos Aires, Ciudad de México y Madrid. Santiago de Chile: Instituto de Geografía, Pontificia Universidad Católica de Chile; Madrid: Departamento de Ciencia Política y Relaciones Internacionales, Universidad Autónoma de Madrid.

Peyloubet, P., Barea, G., y O’Neill, T. (2006). Hábitat popular. Resistencia cultural materializada. Revista INVI, 21(57), 62-73. Recuperado de http://www.revistainvi.uchile.cl/index.php/INVI/article/view/303/908

Russell, R. y Tokatlian, J. G. (2003). De la autonomía antagónica a la autonomía relacional: una mirada teórica desde el Cono Sur. Perfiles Latinoamericanos, 21, 159-194.

Rojas, M. y Villagran, G. (2008). Procesos urbanos informales e intervención publica. El caso del Programa Ribera Norte. Revista Bitácora, 13(2), 133-150.

Sabatini, F. (2000). Reforma de los mercados de suelo en Santiago de Chile: efectos sobre los precios de la tierra y la segregación residencial. Revista EURE, 26(77), 49-80. https://doi.org/10.4067/s0250-71612000007700003

Salinas, E. y Pérez, L. (2011). Procesos urbanos recientes en el Área Metropolitana de Concepción: transformaciones morfológicas y tipologías de ocupación. Revista de Geografía Norte Grande, 49, 79-97. http://dx.doi.org/10.4067/S0718-34022011000200006

Sampieri, R., Fernández, C., y Baptista, M. (2007). Metodología de la investigación. Recuperado de https://www.esup.edu.pe/descargas/dep investigacion/Metodologia\%20de\%20la\%20investigaci\% C3\%B3n\%205ta\% 20Edici\% C3\%B3n.pdf

Servicio de Vivienda y Urbanismo, Serviu. (2014). Carta de respuesta a solicitud de listado familias PRN por Ley de transparencia.

Sequera, J. (2015). A 50 años del nacimiento del concepto de gentrificación. La mirada anglosajona. Biblio 3W, Revista Bibliográfica de Geografía y Ciencias Sociales, 20(1), 1-23. Recuperado de http://www.ub.edu/geocrit/b3w-1127.pdf

Theodore, N., Peck, J., y Brenner, N. (2009). Urbanismo neoliberal: la ciudad y el imperio de los mercados. Temas Sociales, 66. Recuperado de http://www.sitiosur.cl/r.php?id=898

Vainer, C. (2000). Pátria, empresa e mercadoria: notas sobre a estratégia discursiva do planejamento estratégico urbano. Petrópolis: Vozes.

Zunino, H. (2005). Construyendo ciudad desde lo local en lo global: el caso del Proyecto Ribera Norte, Concepción, Chile. Scripta Nova, Vol. IX, 194(86). Recuperado de http://www.ub.edu/geocrit/sn/sn-194-86.htm 